\title{
Q. Linguagens
}

\section{A FITA DE MOEBIUS OU A EXPERIÊNCIA INFINITA: DESCONSTRUÇÃO E DESCOLONIALIDADE NA OBRA DE CAROLA SAAVEDRA ${ }^{1}$}

\author{
ILSE MARIA DA ROSA VIVIAN (UFSM)
}

RESUMO: A figuração do homem, ao problematizar a violência do passado e reinscrevê-la, transgredindo fronteiras de tempo e de espaço e rompendo com subversão da tradição do silêncio e do esquecimento, instaura um reordenamento ideológico que vai de encontro às antigas significações da colonialidade, por longo tempo tão perpetuadas no imaginário brasileiro. Mediante as representações do mundo contemporâneo, cujas complexas relações instauram-se entre subjetividades, etnias, religiões e nacionalidades, proponho a apresentação do estudo da obra Com armas sonolentas (2018), de Carola Saavedra, com o objetivo de, pelo viés da Teoria da Narrativa, dos Estudos Culturais e Pós-coloniais, sob uma perspectiva fenomenológica, analisar o movimento de (re/des)construção da memória e suas aproximações com as epistemologias chamadas Descoloniais.

PALAVRAS-CHAVE: Literatura Brasileira. Narrativa contemporânea. Memória. Descolonialidade. Carola Saavedra.

ABSTRACT: The figuration of man, by problematizing the violence of the past and reinscribing it, transgressing borders of time and space and breaking with the subversion of the tradition of silence and forgetfulness, establishes an ideological reordering that goes against the old meanings of coloniality, perpetuated for so long in the Brazilian imaginary. Through the representations of the contemporary world, with complex relationships that are established among subjectivities, ethnicities, religions and nationalities, I propose the presentation of the study of Carola Saavedra's work Com armas sonolentas (2018), with the objective of, from the Theory of Narrative, the Cultural and Postcolonial Studies, from a phenomenological perspective, analyze the movement of memory (re/de)construction and its approximations with the so-called Decolonial epistemologies.

KEYWORDS: Brazilian literature. Contemporary narrative. Memory. Decoloniality. Carola Saavedra.

\footnotetext{
${ }^{1}$ O presente trabalho foi realizado com apoio da Coordenação de Aperfeiçoamento de Pessoal de Nível Superior Brasil (CAPES) - Código de Financiamento 001. This study was financed in part by the Coordenação de Aperfeiçoamento de Pessoal de Nível Superior - Brasil (CAPES) - Finance Code 001.
} 


\section{S. Linguagens}

\section{CONSIDERAÇÕES INICIAIS}

$\mathrm{O}$ estudo que apresento tem por pressuposto que a existência da $\operatorname{pessoa}^{2}$ na ficção contemporânea é um fenômeno que sistematiza uma percepção do $s i^{3}$ e do mundo marcado pela recorrência de estratégias narrativas que têm como cerne o tempo e sua arquitetura em linguagem. A estruturação da personagem e os significados decorrentes de sua formulação, na narrativa contemporânea, respondem às experiências culturais da diáspora que caracteriza o século XXI. Nesse sentido, a figuração, pela forma como sistematiza simbolicamente dado universo, humanizando o tempo e recriando a própria vida, constitui-se como a exteriorização de um discurso cultural e político de alteridade que explicita a dialética do desejo humano de pertença e libertação.

Meu percurso de investigação da estética das identidades na literatura contemporânea teve início na minha dissertação de mestrado, que versou sobre o estudo do discurso ideológico da personagem no romance português, e teve sequência e aprofundamento na pesquisa realizada durante o período de doutoramento, onde desenvolvi a tese da "personagem-memória"4, tomando por base o corpus das Literaturas Africanas e, portanto, nas suas relações com o Colonialismo, Neocolonialismo e os Imperialismos, cujas políticas são fulcrais à formulação dos processos identitários tematizados na obra do autor Mia Couto.

Com base nesse trajeto feito de deslocamentos culturais e consequentes revisões sobre a minha condição histórica e o contexto histórico que vivemos, volto meu olhar para a produção literária brasileira contemporânea, ao verificar que o movimento de (des)construção da memória e suas relações com a diáspora é um constituinte fundamental nas narrativas produzidas

\footnotetext{
${ }^{2} \mathrm{O}$ conceito de pessoa, desenvolvido na obra Pessoa e personagem, de Michel Zéraffa (2010), origina-se de um modo de constatação da realidade associado à determinada visão da existência humana: "entre a pessoa possível, ou essencial, e as dificuldades que se opõem à sua realização, a personagem é mediadora".

${ }^{3}$ Em O si-mesmo como um outro (1991), Ricoeur concebe que a categoria da personagem carrega a problemática da identidade pessoal e compreende a existência da pessoa na narrativa como produto do significado construído pela articulação do narrado com a operação narrativa.

${ }^{4}$ Disponível em:

http://repositorio.pucrs.br/dspace/bitstream/10923/6808/1/000461224-Texto\%2BCompleto-0.pdf
}

Linguagens \& Cidadania, v. 21, n. esp., jan./dez. 2019 - art. 4 pág. 2 


\section{Q. Linguagens}

recentemente no Brasil por um grupo de escritores. Levanto a hipótese de que a figuração do homem na obra brasileira contemporânea, ao problematizar o passado e suas violências e trazê-los à cena, instaura um reordenamento ideológico que vai de encontro às antigas significações da colonialidade ${ }^{5}$, por longo tempo tão perpetuadas no imaginário brasileiro.

O cruzamento temático proposto pressupõe o recorte de narrativas em primeira pessoa, já que a temporalização que surge em nome de uma dimensão subjetiva que se põe a narrar, pela dinâmica narrativa (cf. teoria de Ricoeur, 1991, 2007, 2010), possibilita o acesso a uma realidade de ser que escapa às perigosas invenções unitárias ou totalizadoras da razão. Elege-se, assim, como corpus a ser tratado aqui o romance Com armas sonolentas (2018), de Carola Saavedra.

A autora da narrativa que tomo por objeto integra um grupo de escritores que se caracteriza pela crítica da matéria que põe em relação passado e presente. A eleição dos autores que integram a minha pesquisa de pós-doutoramento, cujo trabalho exponho em parte nesse artigo, foram selecionados com base em três critérios: são produtores de uma obra que está sendo lida no Brasil e no exterior (são traduzidas em diversos países), de forma que são ativos na construção do imaginário cultural brasileiro; tematizam a perda das identidades e a necessidade de aliança com a atualidade, o que os coloca o desafio de reinventar tanto a composição das subjetividades como as formas históricas do realismo literário; e, sobretudo, tratam das questões mais vulneráveis da contemporaneidade: a violência contra o sujeito estabelecida pelas relações de poder, a urgência do sujeito de existir e o movimento dialético do desejo de pertença/libertação que subsiste à miséria e à opressão.

Esses critérios relacionam-se com os argumentos descoloniais que já vem sendo debatidos por muitos estudiosos desde o século XIX. O pensamento anterior e as redefinições do atual contexto permitem, assim, enormes avanços nesse sentido. A literatura, enquanto pensamento

\footnotetext{
${ }^{5}$ Conforme Eduardo Restrepo, na obra Inflexión decolonial: fuente, conceptos y cuestionamientos (2010), diferente do colonialismo "la colonialidad es um fenómeno histórico mucho más complejo que se extiende hasta nuestro presente y se refiere a um patrón de poder que opera a través de la naturalización de jerarquias territoriales, raciales, culturales y epistémicas, possibilitando la re-production de relaciones de dominación.”.
} 


\section{S. Linguagens}

crítico produzido nas fronteiras, é capaz de trazer respostas epistemológicas ao presente, uma vez que se instaura quando o indefinível pode ser simbolizado e se dissemina. O imaginário é o dispositivo disponível no instante singular em que as perguntas não encontram respostas e não querem ser silenciadas.

O processo de descolonização, conceito que adoto para pensar a rearticulação do imaginário do sujeito que se orienta no percurso do reconhecimento, tem origem na teoria de Fanon (2002) e, mais especificamente direcionado à América Latina, no pensamento de Eduardo Restrepo (2010, p.47), já que considero, assim como afirma esse último, que

el colonialismo no hay que entenderlo sólo como los aparatos militares y administrativos para la dominación física de unas poblaciones y geografías, sino también como los discursos de inferiorización de los colonizados. Esta inferiorización no es sólo uma 'representación' de los europeos sobre las poblaciones dominadas, sino que implica el socavamiento de las condiciones de reproducción de sus 'sistemas de referencia' (la 'desculturación').

Anibal Quijano (2005) compreende os processos de descolonialidade como as construções culturais produzidas pelos sobreviventes do massacre promovido por forças imperialistas, que os submeteram e ainda os submetem a uma repressão material e subjetiva, forçando a desaparecer qualquer relação imaginária com o passado colonial. Essa condição pode ser observada nas experiências dos milhares de imigrantes europeus e traficados africanos que compõem as sociedades no mundo.

Entendo, assim, a descolonialidade como uma proposta de alteridade construída nas relações de dominação dos tempos modernos, que produziu pela colonialidade do poder a subalternização do saber e da vida social. Essa alteridade constitui-se como uma diferença da subjetividade do ser em confronto com a crítica ao desenvolvimento do capitalismo global na produção de suas exterioridades, cujo processo, conforme Walter Mignolo (2007, p.27), é "la energía que no se deja manejar por la lógica de la colonialidad, ni se cree los cuentos de hadas de la retórica de la modernidad". 


\section{Q. Linguagens}

Objetivo, dessa forma, com a aproximação entre a análise dos processos de produção de subjetividades na narrativa brasileira e a crítica dos Estudos Culturais, redimensionar e avaliar a categoria da personagem enquanto constructo imaginário que, além de emitir um ponto de vista sobre o homem e sua posição no mundo, pode ou não naturalizar, desconstruir ou legitimar determinadas relações de poder. Nesse sentido, o corpus eleito para a pesquisa se justifica por trazer ao primeiro plano na trama das subjetividades o cenário político brasileiro, a culturalização das experiências sociais, a reinvenção do passado no presente, o lugar do migrante latino-americano e a violência de gênero.

Pode-se afirmar, considerando-se a estética dos romances desses autores, que se trata de uma geração pós-moderna que tem como cerne de sua escritura a reivindicação de identidades, como afirma Karl Erik Schollhammer (2011, p.29):

Apesar de representar um retorno aos temas tradicionais da fundação da nação, da história brasileira e do desenvolvimento de uma identidade cultural, esses romances [refere-se aos romances produzidos a partir da década de 80] representam, ao mesmo tempo, uma reescrita da memória nacional da perspectiva de uma historiografia metaficcional pós-moderna, valendo-se frequentemente da irreverência nesse trabalho.

Com armas sonolentas (2018), romance lançado em 2018 por Carola Saavedra, apresenta o complexo processo de (des)construção do eu, num mundo que se caracteriza pela confusão e perecibilidade das identidades. Três mulheres vivenciam o exílio, o abandono e a opressão num desencontro de línguas, lugares e experiências: a enérgica Anna, aspirante a atriz, de origem humilde, experiencia a diáspora ao ir viver na Alemanha, questionando, assim, sua identidade; a melancólica Maike, que é alemã, mas apaixonada pela língua portuguesa, vive a crise de não se reconhecer na própria cultura e encontrar no Brasil a própria origem; e uma menina de catorze anos, que é obrigada pela mãe a deixar sua casa no interior de Minas para trabalhar como doméstica numa casa de família no Rio de Janeiro, retrata uma nova configuração de identidade a partir das relações de poder aí estabelecidas. Os deslocamentos, representados pela narrativa fragmentada, sejam emocionais ou sejam geográficos, desencadeiam o desejo de "voltar para 


\section{W Linguagens}

casa", ou seja, o desejo de desvendar as identidades e suas possíveis formas de articulação no mundo.

\section{COM ARMAS SONOLENTAS}

O romance divide-se em duas partes: "O lado de fora" e "O lado de dentro". Ambas são fragmentadas com os subtítulos Anna, Mike e (Avó), o que cria a ilusão, à primeira vista, que as narrativas são independentes, tematizando, cada uma, a vida dessas mulheres. Em "O lado de fora", da perspectiva do presente, uma voz, que constantemente se dilui para sobressair a consciência de Anna, volta-se para o passado para narrar as experiências daquela que, com 21 anos, sonha com uma carreira de atriz, o que lhe pareceu possível alcançar quando conheceu um diretor de cinema alemão, embora o narrador onisciente já antecipe o emaranhado de promessas e enganos a que se precipita a personagem:

Sempre lhe pareceu que havia uma dissonância entre o que desejava e o que realmente queria. Como se todo desejo viesse encoberto por uma espessa camada de autoengano, um inevitável mal-entendido. E satisfazer suas vontades ou vê-las satisfeitas nada mais era do que o prenúncio de uma queda, cada vez mais célere, cada vez mais íngreme. $\mathrm{E}$ assim, a cada sucesso, uma fagulha de infelicidade se imiscuía, lenta e imperceptível. Não que não intuísse que algo ia mal, porque no fundo ela soube desde o início. (SAAVEDRA, 2018, p.13)

A narrativa de Mike, em primeira pessoa, inicia com a sua decisão de estudar português ao invés do curso de Direito para o qual havia ingressado, contrariando a tradição da família alemã, de mãe e pai advogados. A decisão the revela algo mais do que a simples recusa em compartilhar do universo de aparências vivido pela mãe "que era toda brilho e superfície, toda Chanel, toda Yves Saint Laurent" e "por dentro, aquela massa escura de enganos".

$\mathrm{O}$ curso do idioma estrangeiro proporciona a Mike conhecer Lupe, a colega mexicana por quem se apaixona e se redescobre: "havia algo escrito em mim sem que eu soubesse, algo que eu mesma não havia lido". (SAAVEDRA, 2018, p.82). É Lupe quem também reacenderá a dúvida de Mike sobre sua genealogia, "aquilo me incomodou, como sempre me incomodava quando 


\section{Q. Linguagens}

faziam esse comentário, você não parece alemã, ou me perguntavam de onde eu era, definitivamente a pele morena era um elemento incompatível com a Alemanha." (SAAVEDRA, 2018, p.78) A lembrança do episódio trágico da infância, em que o amigo lhe enfiara uma faca nas costas enquanto brincavam, insistindo em afirmar que ela não existia, leva Mike a procurá-lo:

- Quero dizer o que estou dizendo, é que sua origem, e preste bastante atenção nessa palavra, origem, a sua origem está em outro lugar, qualquer um com um pouco de entendimento percebe isso, basta olhar para você. [...]

- Não ria, Mikezinha, eu sei o que estou dizendo. A sua origem está lá. [no Brasil] Sua origem e seu destino. (SAAVEDRA, p.120-1; grifo da autora)

A terceira parte de "O lado de fora", intitulada "(Avó)" consiste na narrativa de uma mulher cujo nome não é dado ao leitor, que, com 14 anos, dirige-se, sem outra opção mediante a pobreza da família, para o Rio de Janeiro para trabalhar como doméstica para uma família de classe média. Muito ligada à Avó, de origem indígena, relembra seus ensinamentos como forma de resistir ao sofrimento, à solidão, à violência e ao abandono durante a adaptação naquele lugar “onde era quase invisível” (SAAVEDRA, 2028, p.144). "Até que dois acontecimentos fizeram com que o tempo mudasse de rumo. O primeiro foi a morte da Avó" (SAAVEDRA, 2018, p.143) e o segundo a gravidez, fruto dos abusos do filho mais velho de D. Clotilde, a patroa. Silenciada, em troca de não ser expulsa da casa e não ter que abrir mão da criança, "ela sentiu vontade de nunca ter existido" (SAAVEDRA, 2018, p.158). Passa a compartilhar das visitas da avó morta, cuja voz lhe revela a sabedoria dos ancestrais indígenas, recitando, às vezes, trechos da carta de Sor Juana Inés de la Cruz ${ }^{6}$.

Ao final da primeira parte do romance Com armas sonolentas, embora a narrativa aconteça em três épocas distintas, já se observa, embora ainda não explicitado o parentesco entre

\footnotetext{
${ }^{6}$ Ao longo do romance são evocados por diversas vezes os textos de San Juan de la Cruz, o poema "Primero sueño" e a carta "Respuesta a Sóror Philotea de la Cruz", essa dirigida ao prelado mexicano, escrita em fins do século XVII, onde se lê a defesa do direito de estudo para as mulheres e a validade do conhecimento laico. Esses paratextos indiciam tanto os diálogos culturais abertos pela narrativa quanto as complexas problemáticas sociais e políticas que vão ganhar dimensão nas figuras das quatro personagens, corpos invisíveis que só ganham existência, "densa e clandestina", nas brechas discursivas de uma cultura etnocêntrica, patriarcal e heteronormativa.
} 


\section{Vinguagens}

as quatro personagens, que experiências comuns estreitam os laços entre essas três mulheres: a violação física e moral, a invisibilidade social e a extrema necessidade de (re)construção das identidades. Se a realidade é a trama das promessas, dos enganos, das ausências, dos abandonos e das violências, nos limiares transcorrem os sonhos, os devaneios, os desejos, os fantasmas.

A narrativa transita, assim, do querer ser, dos desejos de cada uma das personagens às possibilidades de existência. A resistência é manifestada pela própria impotência de ser o que se deseja, que desaloja cada uma dessas três mulheres das estruturas hierarquizantes impostas pelo enquadramento social:

a autocomiseração era substituída pela raiva, como era possível?, afinal, ela era uma atriz de talento, casada com um diretor famoso, um homem importante, havia largado tudo por ele, e em vez de se tornar sua musa, ou ao menos ter um papel de menor importância, ela a enterrava ali, naquele fim de mundo. Quem ele achava que era? [...] (SAAVEDRA, 2018, p.38)

o que Anna sentia era um desânimo tão grande, a sensação de que ela não era mais uma atriz, e, se ela não era mais uma atriz, o que restava era muito pouco, quase nada, uma tristeza, uma melancolia [...] Foi se encolhendo e ficou longos minutos ali sentada, talvez horas, a sensação de que algo se rompera em seu corpo, uma artéria imaginária. (SAAVEDRA, 2018, p.44)

A impotência de Anna e Mike frente às privações do universo instituído desvela a potência de algo de si mesmas que deve ser descoberto, no sentido fenomenológico dessa palavra. Não ser é a arma para resistir à invisibilidade do eu produzida pelo outro. Dito de outro modo, o próprio processo de apagamento das identidades leva cada uma aos significados que indiciam o caminho da descoberta.

O conflito com o mundo exterior vivido pelas personagens é apenas um dos elementos no percurso que abrange a busca existencial, cuja formulação, sempre em devir, realiza-se no vai e vem entre as esferas interior/exterior e, sobretudo, no limiar desses universos. Os deslizamentos a que são submetidos o leitor a partir das conexões necessárias para a construção de significados das personagens realizam, no mínimo, dois efeitos: primeiro, há o descentramento da visão sobre cada personagem, e, portanto, destituição de valor de qualquer noção que pressuponha uma 


\section{Q. Linguagens}

verdade unilateral do ser. Isso ocorre porque a segunda parte da obra, com uma estrutura que espelha a primeira, oferece, sob diferentes óticas, novas percepções sobre o lugar ocupado por uma personagem na história de vida da outra. Consequentemente, cada uma delas modifica a própria percepção de si e do outro. A multiplicidade dos relatos posiciona cada figura numa situação a que se pode chamar entre, lugar de enunciação que tende à desconstrução do instituído, que tende a

reverter a ontologia, destituir o fundamento, anular fim e começo. [...] Entre as coisas não designa uma correlação localizável que vai de uma para outra e reciprocamente, mas uma direção perpendicular, um movimento transversal que as carrega uma $e$ outra, riacho sem início nem fim, que rói suas duas margens e adquire velocidade no meio. (DELEUZE, 2011, p.49)

A organização da narrativa reflete o quão intercambiável pode ser o discurso de "O lado de dentro e de "O lado de fora", de modo que as multiplicidades de sentidos que coexistem penetram-se e alteram constantemente a imagem de cada figura. A proposta de deslizamentos na construção de significados, que sobrepõe ou atravessa a figura de uma personagem sobre a outra, coloca em questão, portanto, a origem, os limites ou a finitude de cada figura, tornando-as agentes de uma enunciação que se constrói de forma coletiva:

não existe enunciado individual, nunca há. Todo enunciado é o produto de um agenciamento maquínico, quer dizer, de agentes coletivos de enunciação (por "agentes coletivos" não se deve entender povos ou sociedades, mas multiplicidades). Ora, o nome próprio não designa um indivíduo: ao contrário, quando o indivíduo se abre às multiplicidades que o atravessam de lado a lado, ao fim do mais severo exercício de despersonalização, é que ele adquire seu verdadeiro nome próprio. O nome próprio é a apreensão instantânea de uma multiplicidade. O nome próprio é o sujeito de um puro infinitivo compreendido como tal num campo de intensidade. (DELEUZE, 2011, p.65-6)

Eis o segundo efeito, a superfície da narrativa é tomada por uma voz que se faz coletiva. O que poderia significar o encerramento de cada imagem na expressão da interioridade, com suas histórias isoladas, na primeira parte da narrativa, ora em terceira, ora em primeira pessoa, é subvertido na segunda parte da obra, e, em decorrência da ramificação de perspectivas, tudo que era encoberto torna-se manifesto, ganhando a superfície do discurso. A estrutura do romance 


\section{W Linguagens}

dobra-se em si mesma, recalcando toda e qualquer possibilidade de compreensão que pressuponha linearidade, protagonismo individual, relação de causalidade ou individualidade. A travessia de "O lado de fora" para "O lado de dentro" e vice-versa é, portanto, infinita, simbolizada na narrativa pela fita de Moebius ${ }^{7}$, referência que aparece pela voz de Anna, quando se dirige ao público para contar seu sonho:

A menina segura nas mãos uma tira de papel, torce-a uma vez e, após torcê-la cola as duas extremidades. Depois pega uma tesoura e corta a fita ao meio no sentido do comprimento, continua cortando e, ao se aproximar do ponto de partida, em vez de encerrar o trajeto dividindo a fita em dois pedaços, ela faz um pequeno desvio, e, sem afastar a tesoura do papel segue em frente [...] A menina tem cada vez mais dificuldade em continuar, vejo que a fita vai se tornando cada vez mais fina, e a possibilidade de rompê-la sem querer, cada vez mais provável.[...] Quando ela finalmente se detém, ergue na minha direção uma longa fita e diz, não tenha medo, o lado de dentro ainda é o lado de fora. (SAAVEDRA, 2018, p.186)

A multiplicação e abertura em miríades do relato da memória impede a fixidez das imagens de cada mulher ao mesmo tempo em que as conexões entre elas expandem a construção de uma figura em relação a outra. A proposta de leitura às avessas pressupõe, dessa forma, a des-subjetivação e a infinitude dos sentidos projetados por cada uma sobre a outra, dando lugar, pelas conexões entre as quatro histórias, a uma enunciação em que as subjetividades têm valor especial, mantidas as diferenças, por serem coletivas: "O lado de dentro", título da segunda parte, torna-se o "O lado de fora", título da primeira parte da narrativa. Já não é possível ao leitor conhecer a Anna, Mike, a mãe de Anna ou a Avó senão pela alteridade construída, na contramão da identificação, pelo desencontro e pela diferença.

A recusa às linhas que demarcam o sujeito, suas origens, finitude e fronteiras, expressa-se, também, a partir da eleição do espaço da enunciação. Anna, na segunda parte da narrativa, utiliza o teatro para contar sua história de vida, compondo-se, portanto, nos limites dos discursos do que

\footnotetext{
${ }^{7}$ A fita de Moebius é um espaço topológico obtido pela colagem das duas extremidades de uma fita, após efetuar meia volta em uma delas. Deve o seu nome a August Ferdinand Möbius, que a estudou em 1858. Representa um caminho sem fim nem início, infinito, onde se pode percorrer toda a superfície da fita que aparenta ter dois lados, mas só tem um.
} 


\title{
Q. Linguagens
}

se convenciona pontuar como real e ficção. A narrativa de si a partir do limiar faz contraponto às práticas culturais que, ao longo da história da produção do conhecimento, fixam e determinam os territórios discursivos conforme as intenções de determinadas instâncias de poder. Conforme Ricardo Barberena (2014, p. 9-10), habitar o limiar significa

\begin{abstract}
a aceitação de que também existem falências na homologação de uma caminhada absolutizada por uma condição de interioridade ou exterioridade. O proteger-se no "entre" passa a ser uma estratégia de sobrevivência que rechaça as territorialidades fendidas pela arbitrariedade das fronteiras conceituais. A guarida sob a égide de um local de indeterminação binária possibilita uma aquiescência do contágio e da mobilidade enquanto forças de significação em errância.
\end{abstract}

$\mathrm{Na}$ figura do fantasma, a Avó, símbolo da sabedoria ancestral, concentra-se a problemática tanto da origem quanto da finitude. Após a morte, a Avó alcança a "conexão" e "se desvincula" da ordem causal (destino) a que era subjugada. Narrar si mesmo, tomando consciência das suas heranças, é o modo, proposto pela personagem, pelo qual "se pode se aproximar da sua essência original”. É pela figura do fantasma que se apresenta uma alternativa como solução à questão levantada ao longo de toda a narrativa: "somos a herança, uma herança gravada nas palavras de nossos ancestrais".

A natureza do fantasma permite-lhe uma existência em trânsito, "nem ativos nem passivos, nem internos nem externos, nem imaginários nem reais, os fantasmas têm realmente a impassibilidade e a idealidade do acontecimento" (DELEUZE, 2015, p.218). A sua situação com relação ao seu eu é ausente de partição, ou seja, para o fantasma está abolida a separação entre ele e o mundo, de modo que um traço que o caracteriza é a ausência de subjetivação. Nas palavras de Deleuze (2015, p.220), “o que aparece no fantasma é o movimento pelo qual o eu se abre à superfície e libera as singularidades acósmicas, impessoais e pré-individuais que aprisionava.” A aniquilação da subjetividade e a legitimidade simbólica do originário, acósmico, é o recurso apresentado para reconhecer a narrativa de si mesmo e "reencontrar a antiga conexão, ou seja, fazer a travessia. 


\title{
W. Linguagens
}

Realiza-se, na figura do fantasma, um marco onírico semelhante ao do poema de Sór Juana de La Cruz, evocado pelo título do romance, a alma abandona o corpo para poder, enfim, com liberdade existir. Ironicamente, o sentido de existência é questionado pela personagem "criatura-ninguém" (HILST apud SAAVEDRA, 2018, p.7), a mãe de Anna:

\begin{abstract}
e aquilo que ela era se transformava numa roupa que agora tirava, seu nome, seu passado, o lugar onde morava, sentia que o corpo adquiria vida própria, o corpo sabia coisas que não contava a ninguém. Ela olhava em volta assustada, não tanto com o entorno, mas com ela mesma, com as palavras que surgiam [...] a representação do ato invocando o próprio ato, feito palavras mágicas, ou um mundo mais primitivo ainda, no qual as coisas ainda não tinham nome e se misturavam umas com as outras [...] o início do mundo apenas isso, uma palavra compartilhada?, e veio-lhe então um pensamento mais esquisito ainda, e se o início era só uma palavra, o que garantia que ela não perderia, de um momento para outro, o seu significado? quando aqueles que a compreendiam deixassem de existir [...] afinal, o que a diferenciava da avó, que certeza ela tinha da própria existência? (SAAVEDRA, 208, p.256-7)
\end{abstract}

Despida da realidade mundana, despida da imagem feita pelo outro, quando outro deixasse de existir, o que lhe restaria ser? É preciso despir-se do passado sem sentido para alcançar o que é imemorial. O corpo torna-se inscrição, transmuta-se em palavra, mas palavra compartilhada. A única garantia de existência é a construção de uma memória tecida pelas palavras comuns de uma experiência que se faz coletiva.

Toda a arquitetura da narrativa, com a descentralização das imagens das personagens, os deslizamentos propostos pela estrutura, a multiplicação de vozes, o discurso que emerge da relação corpo/ser, encaminha o leitor a transcender a limitação das subjetividades, da lembrança individual, para realizar as conexões das experiências que comungam de um passado "herança". A narrativa da experiência problematiza, então, a reconstituição do passado, colocando no centro do processo a relação que se estabelece com o presente. A garantia de que o passado pode ser revisitado sem que chegue ao presente é a lembrança:

A lembrança insiste porque de certo modo é soberana e incontrolável (em todos os sentidos dessa palavra). Poderíamos dizer que o passado se faz presente. E a lembrança precisa do presente porque, como assinalou Deleuze a respeito de Bergson, o tempo próprio da lembrança é o presente: isto é, o único tempo apropriado para lembrar e,

Linguagens \& Cidadania, v. 21, n. esp., jan./dez. 2019 - art. 4 pág. 12 


\section{S. Linguagens}

também, o tempo do qual a lembrança se apodera, tornando-o próprio. (SARLO, 2007, p.10, grifos da autora)

O passado, nesse contexto, adquire valor como lugar onde se encontram os vestígios que explicam o tempo presente, não podendo, de forma alguma, apoderar-se desse, "pois um acontecimento vivido é finito, ou pelo menos encerrado na esfera do vivido, ao passo que o acontecimento lembrado é sem limites, porque é apenas uma chave para tudo o que veio antes e o depois." (BENJAMIN, 1994, p.37)

As temporalidades expressas por meio de cada personagem, ao longo da narrativa, são projetadas para convergir na figura da Avó, o fantasma, símbolo de um agora imemorial. $\mathrm{Na}$ primeira parte da narrativa, Anna é a personagem que volta-se para o futuro, aspira ser uma grande atriz; Mike, volta-se para o passado, em busca da sua própria origem; na segunda parte da narrativa, Anna volta-se para o passado para resgatar, pela própria voz, a narrativa que a configura no presente; Mike desloca-se para o Brasil e vivencia a terra de origem, que a torna "ao mesmo tempo nativa e estrangeira" (SAAVEDRA, 2018, p.221). Narrar a própria história é o modo pelo qual se pode chegar ao conhecimento de uma experiência de passado que é coletiva e que tem a potência de ser subvertida no agora.

A personagem, nesse sentido, corporifica a desobediência epistêmica em relação à sistematização de pensamento proposta pela modernidade, considerando que:

a modernidade não é definida como um período histórico do qual não podemos escapar, mas sim como uma narrativa (por exemplo, a cosmologia) de um período histórico escrito por aqueles que perceberam que eles eram os reais protagonistas. "Modernidade" era o termo no qual eles espalhavam a visão heroica e triunfante da história que eles estavam ajudando a construir. E aquela história era a história do capitalismo imperial (havia outros impérios que não eram capitalistas) e da modernidade/ colonialidade (que é a cosmologia do moderno, imperial e dos impérios capitalistas da Espanha à Inglaterra e dos Estados Unidos). (MIGNOLO, 2008, p.316-7)

A modernidade disseminou, por meio de suas narrativas, a ilusão do centro e a promessa de futuro, simbolizadas na potência do homem sobre o mundo, na consciência de suas próprias 


\section{Vinguagens}

fronteiras e na confirmação de identidades forjadas por modelos fornecidos por um sistema imperialista. Na contramão dessa proposta, Com armas sonolentas apresenta um novo realismo, cuja verdade só é possível como possibilidade, como desejo ou vontade, e cuja consciência só pode se constituir no próprio processo criativo da experiência em palavra. A escritura do si carrega a dialética contida no ato que, transfigurando-se incessantemente, como na fita de Moebius, realiza-se deslizamentos em que se percorre de maneira infinita um lado e outro. Manifesta-se, simultaneamente, tanto a impossibilidade de apreensão das coisas quanto toda a apropriação contida na experiência de narrar-se.

\section{REFERÊNCIAS}

BENJAMIN, Walter. Magia e técnica, arte e política. Obras escolhidas. Vol. I. Trad. Sérgio Paulo Rouanet. 7. ed. São Paulo: Brasiliense, 1994.

BARBERENA, Ricardo; CARNEIRO, Vinícius (Orgs.). Das luzes às soleiras: perspectivas críticas na literatura brasileira contemporânea. Porto Alegre: Luminara Editorial, 2014.

DELEUZE, Gilles; GUATTARI, Félix. Mil platôs: capitalismo e esquizofrenia. Trad. Ana Lúcia de Oliveira, Aurélio Guerra Neto e Celia Pinto Costa. Vol. I. 2. ed. São Paulo: Ed. 34, 2011.

DELEUZE, Gilles. Lógica do sentido. Trad. Luiz Roberto Salinas Fortes. São Paulo: Perspectiva, 2015.

FANON, Franz. Os condenados da terra. Trad. Enilce Albergaria Rocha,Lucy Magalhães. Juiz de Fora: Ed. UFJF, 2010.

MIGNOLO, Walter D. El pensamiento decolonial: desprendimiento y apertura. Un manifiesto. In: CASTRO-GOMEZ, Santiago; GROSFOGUEL, Ramón. (Comp.).El giro decolonial: reflexiones para una diversidad epistémica más allá del capitalismo global. Bogotá: Siglo del Hombre Editores; Universidad Central, Instituto de Estudios Sociales Contemporáneos y Pontificia Universidad Javeriana, Instituto Pensar, 2007. Disponível em: http://repositorio.pucrs.br/dspace/bitstream/10923/6808/1/000461224-Texto\%2BCompleto-0.pdf

QUIJANO, Aníbal. Dom Quixote e os moinhos de vento na América Latina. Estudos Avançados, v.19, n.55, São Paulo, set./dez. 2005. 


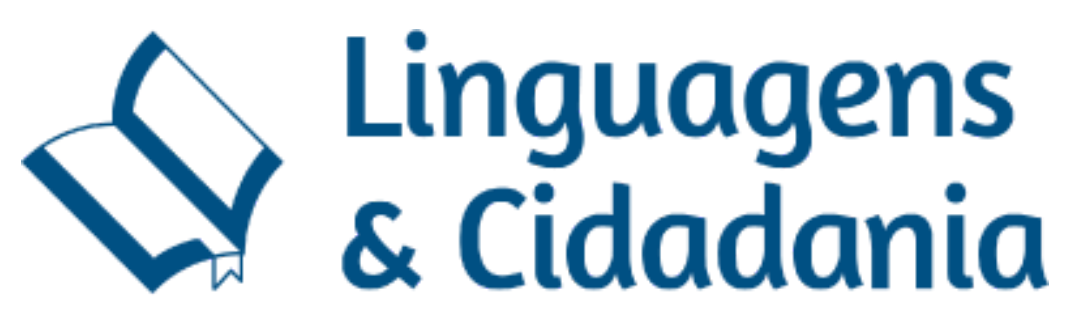

RESTREPO, Eduardo. Infléxion decolonial: fuentes, conceptos y cuestionamientos. Colombia, Cauca: Editorial del Universidad del Cauca, 2010.

RICOEUR, Paul. A memória, a história, o esquecimento. Trad. Alain François [et al.]. São Paulo: Editora da UNICAMP, 2007.

RICOEUR, Paul. O si-mesmo como um outro. São Paulo: Papirus, 1991.

RICOEUR, Paul. Tempo e narrativa. Trad. Claudia Berliner. v. 1, 2, 3. São Paulo: WMF Martins Fontes, 2010.

SAAVEDRA, Carola. Com armas sonolentas. São Paulo: Cia. Das Letras, 2018.

SARLO, Beatriz. Tempo passado: cultura da memória e guinada subjetiva. Trad. Rosa Freire de d'Aguiar. São Paulo: Companhia das Letras; Belo Horizonte: UFMG, 2007.

SCHOLLHAMMER, Karl Erik. Ficção brasileira contemporânea. 2.ed. Rio de Janeiro: Civilização Brasileira, 2011.

VIVIAN, Ilse M. R. A poética da memória: uma leitura fenomenológica do eu em Terra sonâmbula e Um rio chamado tempo, uma casa chamada terra, de Mia Couto. Tese. 187 p. PUCRS, 2014. Disponível em:

http://repositorio.pucrs.br/dspace/bitstream/10923/6808/1/000461224-Texto\%2BCompleto-0.pdf

ZÉRAFFA, Michel. Pessoa e personagem: o romanesco dos anos 1920 aos anos de 1950. Trad. Luiz João Gaia e J. Guinsburg. São Paulo: Perspectiva, 2010. 